\title{
A experiência do adolescente usuário de implante coclear
}

(The experience of cochlear implant adolescent users)

(La experiencia del adolescente que tiene un implante coclear)

\author{
Marcela Maria Bozelli Zanardi* \\ Midori Otake Yamada ${ }^{* *}$ \\ Maria Cecilia Bevilacqua ${ }^{* * *}$
}

\begin{abstract}
Resumo
Este estudo buscou compreender a vida cotidiana de adolescentes com implante coclear. Os participantes da pesquisa foram quatro adolescentes do sexo feminino, entre 13 e 16 anos de idade. Nesta pesquisa qualitativa, a análise dos resultados baseou-se no método fenomenológico. Concluiuse que o contexto escolar era marcado por dificuldades, especialmente na língua portuguesa; o contexto familiar era vivido como espaço de apoio; o namoro/ficar era permeado por sentimentos de inferioridade e marcado pelo preconceito. A importância da amizade era evidente para os adolescentes, e o implante coclear significava satisfação em ouvir e a constatação da deficiência auditiva.
\end{abstract}

Palavras-chave: adolescente; implante coclear; deficiência auditiva.

\begin{abstract}
This study aims to analyze the routine of adolescents with cochlear implant. The participants were 4 female adolescents from 13 to 16 years of age. In this qualitative research, data analysis was based on the phenomenological method. It was concluded that school life was surrounded by difficulties, mainly in Portuguese language; family life was
\end{abstract}

\footnotetext{
Texto recebido em abril/2008 e aprovado para publicação em fevereiro/2009.

Psicóloga, especialista em Psicologia Clínica e Hospitalar pelo Hospital de Reabilitação de Anomalias Craniofaciais da Universidade de São Paulo (HRAC/USP), Bauru/SP - USP, e-mail: marcelazanardi@yahoo.com.br

** Psicóloga do HRAC/USP e mestre do Programa de Pós-graduação em Distúrbios da Comunicação Humana, HRAC/USP, Bauru/SP - USP, e-mail: miotake@centrinho.com.br

${ }^{* * *}$ Professora titular da Universidade de São Paulo - Campus Bauru, fonoaudióloga do HRAC/USP/Bauru - USP, e-mail: cecilia@implantecoclear.com.br
} 
regarded as a place of support; and dating was marked by prejudice and feelings of inferiority. The importance of friendship to the adolescents was evident, and the cochlear implant meant the satisfaction to hear and the acknowledgement of a hearing impairment.

Key words: adolescents; cochlear implant; hearing impairment.

\section{Resumen}

En este estudio se trató de comprender la vida cotidiana de los adolescentes que tienen un implante coclear. Los participantes de la pesquisa fueron cuatro adolescentes del sexo femenino, entre los 13 y 16 años de edad. En esta pesquisa cualitativa, el análisis de los resultados se basó en el método fenomenológico. Se concluyó que el contexto escolar estaba marcado por las dificultades, especialmente en lengua portuguesa; el contexto familiar era un espacio de apoyo; el noviazgo/salir con un chico/a estaba permeado por sentimientos de inferioridad y marcado por prejuicios. Era evidente la importancia de la amistad para los adolescentes, y el implante coclear significaba, al mismo tiempo, la satisfacción de oír y la constatación de la deficiencia auditiva.

Palabras clave: adolescente; implante coclear; deficiencia auditiva.

\section{Introdução}

A adolescência implica um desabrochar de possibilidades inéditas, de novas formas de relação homem-mundo. No plano dos afetos, o sujeito apresenta uma história vivencial que o sensibiliza para certos objetos e o condiciona a vincular-se de determinada maneira (Romero, 2005). Nesse sentido, o plano afetivo apresenta uma relativa primazia sobre os outros planos, visto que não só irradia para todas as dimensões humanas como também apresenta um percurso que se origina no início da infância. $\mathrm{Ou}$ seja, a experiência mais significativa do sujeito se estrutura sob o cunho dos fatores afetivos, pois é nessa fase que se sente impelido a experimentar tudo o que a vida pode oferecer e encontra-se inclinado a experimentar as inúmeras possibilidades de interagir com o mundo.

$\mathrm{Na}$ adolescência, a intensidade emocional e a variação do estado de ânimo dependem, em grande parte, da necessidade que o jovem tem de encontrar seu lugar no mundo e de inserir-se nos diversos planos da existência (amor, 
família, amigos, trabalho). É uma fase na qual cabe cumprir tarefas que lhe são inerentes para, assim, encaminhar-se pelas vias evolutivas adequadas.

Para Justo (2005), mais do que em outras idades, a adolescência expressa as tendências e contradições de um tempo, lugar ou história da sociedade e da cultura, por causa da maior exposição e sensibilidade dos jovens às questóes e idiossincrasias da contemporaneidade. $\mathrm{O}$ adolescente não tem, como o adulto ou idoso, um lastro de defesas egoicas capaz de aliviar o impacto, na subjetividade, de mudanças no cenário socioeconômico e cultural.

Comoetapavital, aadolescência planta novos desafios paraodesenvolvimento humano e a promoção do bem-estar. As tarefas evolucionárias da adolescência - especialmente a configuração da identidade, a busca de autonomia, a tomada de decisões, a privacidade, o aumento do próprio espaço no âmbito social - regulam o comportamento para a realização de objetivos significativos e permitem ao jovem autodirigir-se (Guzman, 2007).

Nesse sentido, como é o adolescer para os que usam o Implante Coclear (IC)? Onde eles se encontram, tendo como pano de fundo um "mundo visual", em que o culto ao corpo é predominante? Como se dá a relação com o outro? Qual a imagem que têm de si?

Conhecer como esses adolescentes estão vivendo, como é para eles o namorar, o estudar, o IC, a percepção que eles têm da experiência com o IC foram objetivos deste estudo. Dessa maneira, inicialmente se realizou uma pesquisa a respeito de temas ligados à adolescência e ao IC.

A literatura é limitada, especialmente no que se refere a esse tipo de enfoque. Huber (2005) referiu não ter encontrado publicaçôes sobre qualidade de vida e resiliência de crianças e adolescentes com IC, tema de sua investigação.

Sabe-se que o IC é um recurso poderoso no tratamento da deficiência auditiva de perdas severa/profunda e que pode ser realizado em pessoas com surdez pré-lingual, que adquiriram deficiência auditiva antes da aquisição da linguagem, e pós-lingual, que a adquiriram após a aquisição da linguagem.

O IC é constituído por dois componentes: interno e externo. O componente interno, inserido cirurgicamente, é composto por uma antena, um receptorestimulador e um cabo multicanal de eletrodos. O componente externo é formado pelo processador de fala e antena transmissora (Costa Filho \& Bevilacqua, 2006).

Para a realização dessa cirurgia, é necessário que se faça uma avaliação pré-implante por uma equipe interdisciplinar, nas áreas de Fonoaudiologia, Psicologia, Serviço Social, Otorrinolaringologia, Pediatria, Neurologia e áreas 
adicionais, caso seja necessário. Durante o processo de avaliação, o paciente e a família recebem orientações da equipe sobre o pré, peri e pós-cirúrgico, para que tenham informações sobre o IC e o programa oferecido, e compreendam o seu funcionamento.

De acordo com Bevilacqua et al. (2004), a avaliação psicológica é de fundamental importância durante a etapa pré-cirúrgica de um programa de implante coclear, pois, além de investigar a presença de comportamentos associados à deficiência auditiva, de natureza intelectual ou emocional, ela é capaz de identificar a motivação e a expectativa do indivíduo e da família quanto ao uso do implante.

No trabalho com adolescentes do Centro de Pesquisas Audiológicas (CPA) do Hospital de Reabilitação de Anomalias Craniofaciais de Universidade de São Paulo (HRAC-USP), Murakami et al. (2001) ressaltaram a importância de se avaliar as condições psicossociais - que incluem expectativas, motivação, entre outros aspectos do adolescente e sua família - para garantir também que os adolescentes estejam preparados psicologicamente para a cirurgia e para o processo de ouvir.

Para Nasralla et al. (2008), tratando-se de adolescentes candidatos ao IC, deve-se considerar a demanda dos pais, o contexto familiar, o desejo do próprio adolescente, a sua relação com o grupo social, o que implica suas identificações, como, por exemplo, as suas condições afetivo-emocionais.

Em um estudo com 21 sujeitos com IC, dos quais 6 eram adolescentes, D’Agosta et al. (1999) observaram, após 18 meses de uso de IC, mudanças significativas nas categorias: qualidade de voz, vocabulário e consciência morfossintática, habilidades auditivas, uso de regras comunicativas e iniciativa pessoal, participação grupal. Tais mudanças se refletiram em uma melhor adaptação em casa e na escola; na expressão de ideias, pensamentos e sentimentos; em uma maior adequação ao ambiente diferente do que lhes era comum; no melhor entrosamento com os colegas e professores; e maior independência emocional.

Bosco et al. (1999) realizaram uma pesquisa com seis adolescentes com IC, acompanhados durante 18 meses, que teve como objetivo ampliar os principais aspectos da comunicação. Para isso, usaram jogos fonéticos e jogos de treinamento acústico, mediante os quais os adolescentes atribuíam novos significados aos erros cometidos. As experiências mais significativas levantadas foram a socialização das experiências e dos processos de aprendizagem individual, o relacionamento diretivo entre os adolescentes; discussão dos tópicos de interesse em comum, a ênfase nas opiniōes pessoais, as experiências 
de produções coletivas, o reforço dos relacionamentos interpessoais e a ênfase nas iniciativas individuais.

Tirado Gutiérrez \& Soda Merhy (2001) estudaram as expectativas dos familiares e candidatos ao IC quanto ao seu uso. Notaram que pacientes adolescentes e adultos, assim como os familiares das crianças, acreditavam que o deficiente auditivo deixaria de ser incapacitado auditivamente após a cirurgia. Outros relataram que levaria muito tempo para a aquisição da linguagem e, outros, ainda, entendiam que os implantados não apresentariam problemas para entender a linguagem e para assistir à televisão ou compreender uma conversa ao telefone. Todos os familiares e pacientes do estudo, segundo os autores, afirmaram que o implante terminaria com suas incapacidades.

Murakami et al. (2001) verificaram a relação entre as expectativas prévias, ansiedades e temores de pacientes adolescentes candidatos a IC, e suas avaliações posteriores quanto a ganhos obtidos com o implante. Por meio de entrevistas, as autoras levantaram as expectativas iniciais dos pacientes. Verificaram que, antes da orientação pré-cirúrgica, as noções eram pouco realistas, visto que o IC não permite o retorno da audição aos níveis anteriores à perda auditiva ou atua no sentido de tornar a vida mais feliz. Após orientaçóes sobre o implante, houve modificação nas expectativas e uma maior conscientização sobre o IC e os possíveis resultados, observando-se uma visão mais realista.

No estudo de Huber (2005) sobre resiliência e qualidade de vida de crianças e adolescentes com IC em idade escolar, a autora, por meio de questionários construídos para as famílias, objetivou conhecer mais sobre os estressores familiares e as percepções da família sobre o implante. Os resultados mostraram que crianças entre 8 e 12 anos experimentavam uma qualidade de vida abaixo da média esperada, quando comparado a crianças ouvintes, enquanto os adolescentes entre 13 e 16 anos tinham uma experiência normal de qualidade de vida, esperada para esta fase.

Yamada (2002), ao buscar a compreensão do adulto usuário de IC (sua afetividade e sua experiência após o implante), verificou que, passar a ouvir por meio do implante tem um significado especial, pois possibilita à pessoa entrar no mundo sonoro, diminuir sua angústia, ampliar sua comunicação com o outro e mudar sua visão de mundo. $\mathrm{O}$ estudo apontou mudanças como melhora na autoconfiança, na autoaceitação, no sentimento do próprio valor e disposição, e predominância de sentimentos positivos que se orientavam para a satisfação do eu. No entanto, para alguns, a unidade externa do IC, assim como as dificuldades na comunicação, expunham e confirmavam a deficiência auditiva, algo que os fazia sentirem-se "menos" que os outros e a manifestarem sentimentos de inferioridade e rejeição. 
O tratamento da deficiência auditiva, segundo Seifert et al (2008), tornou-se indispensável na reabilitação de pacientes com deficiência auditiva severa. De acordo com o autor, se crianças deficientes auditivas pré-linguais receberem o IC no início de sua vida, poderão atingir quase o mesmo discurso e o desenvolvimento esperado em condições normais de audição. Porém, o implante é pouco indicado em adolescentes e adultos pré-linguais, pois, nessa idade, ele tem mostrado poucos benefícios.

Segundo Murakami et al. (2001), é importante compreender as dificuldades pelas quais um adolescente candidato a IC pode passar: para ele, é particularmente difícil ajustar-se, face à problemática física e emocional e à possibilidade de usar um implante que deixará mais exposta sua deficiência auditiva, já que o processador de fala contém uma parte externa visível. As autoras enfatizaram a importância de atentar para as expectativas, temores, ansiedades e conflitos diante da possibilidade de ouvir melhor e das demandas de readaptação de sua autoimagem e autoconceito.

Em um estudo que investigou as experiências e as relações sociais de adolescentes deficientes auditivos entre 11 e 18 anos que faziam uso de AASI (aparelho de amplificação sonora individual), Balieiro e Ficker (2001) realizaram um acompanhamento das diversas situaçōes de vida, como família, escola, relacionamentos sociais. As autoras constataram que, para os participantes da pesquisa, o período da adolescência era marcado por uma grande turbulência em relação ao ser diferente, com uma maior conscientização quanto às implicações da surdez. Aspectos inerentes à condição de deficiência auditiva, nessa fase, passavam a fazer sentido, exigindo ajustes conscientes, tolerância e aceitação das situações nas quais a surdez se fazia sentir de forma mais aguda. Quanto ao significado da surdez ou deficiência auditiva, houve uma vinculação entre o termo deficiente auditivo e a possibilidade de ouvir a fala pelo AASI. E, ao se definirem como deficientes auditivos, os participantes não demonstraram que o termo deficiente tinha qualquer conotação pejorativa. Em alguns casos, a solidão do jovem impulsionou a família a assumir uma postura de maior ajuda, muitas vezes preenchendo as necessidades próprias desse período, em razão da dificuldade em estabelecer vínculos fortes de amizade. Isso tornava mais prolongado o convívio com os pais; mas, quando a capacidade de aprendizagem e adequação social foram sendo reconhecidas pelos adolescentes, as famílias puderam adotar uma postura mais livre, ofertando espaço às próprias opções de seus filhos, contribuindo para a passagem à vida adulta.

O Centro de Pesquisas Audiológicas do Hospital de Reabilitação de Anomalias Craniofaciais da Universidade de São Paulo, Campus de Bauru 
(CPA-HRAC-USP-Bauru) desenvolveum trabalhocomgruposdeadolescentes usuários de IC, coordenado pela psicóloga Midori Otake Yamada, que tem por objetivo oferecer um espaço para que possam falar, refletir e discutir suas experiências como usuários de IC. Temas emergentes são trabalhados e, comumente, revelam as facilidades, dificuldades e questôes relativas ao manejo do IC: os benefícios audiológicos que proporciona, a melhora na comunicação com o outro, a possibilidade de participação nas atividades sociais, auxiliando na independência e autoestima. Comentase a respeito da quebra ou defeito em alguma parte do IC, sobre a recirurgia, dificuldades individuais de lidar com a deficiência, a questão de ser diferente, a dependência dos pais, a preocupação com a estética e outros temas. O grupo proporciona troca de experiências comuns, modos diferentes de lidar com as situaçóes e a possibilidade de expressarem os seus sentimentos.

Pensando nesse adolescente e na forma como ele experimenta esse período de sua vida, esta pesquisa objetivou compreender a vida do adolescente com IC dentro de uma perspectiva fenomenológica e delinear como o fenômeno da adolescência é vivido nos diversos contextos: escola, família, amizade, namoro, enfim, questôes que permeiam o fenômeno adolescer.

\section{Metodologia}

Este estudo foi desenvolvido no CPA-HRAC-USP Bauru, com aprovação do Comitê de Ética (Ofício no 147/2006).

O método usado foi o fenomenológico, uma vez que é um recurso apropriado para pesquisar o modo como a experiência é vivida. A investigação fenomenológica trabalha com o qualitativo, com aquilo que faz sentido para o sujeito, o que representa a possibilidade de ampliar a compreensão em relação ao fenômeno indagado, permitindo mostrar, descrever e compreender os fenômenos vividos. Essa abordagem permite ao pesquisador obter uma compreensão segundo a perspectiva dos adolescentes com IC, em relação às suas experiências e situações, expressadas por suas próprias palavras.

O levantamento de dados deu-se por meio de entrevista, norteada pela questão: "Como é para você estar na adolescência usando o implante coclear?”.

Os depoimentos foram gravados, e a pesquisadora interveio com eventuais questionamentos quando estes se fizeram necessários para 
o esclarecimento de dúvidas sobre o tema. Os depoimentos coletados foram analisados conforme orientações de Martins e Bicudo (1989).

O primeiro momento caracterizou-se pela transcrição dos depoimentos, pela leitura de todas as entrevistas, com a intenção de familiarização com a descrição da experiência vivida. $\mathrm{O}$ segundo momento foi marcado pelas leituras e releituras dos depoimentos, ocasião em que a pesquisadora colocou em evidência os significados na descrição, de acordo com a questão da investigação. No terceiro, a pesquisadora obteve a unidade de significação, ou seja, agrupou os depoimentos por categorias, que é a transformação da linguagem coloquial do entrevistado para o discurso psicológico. No quarto momento, a pesquisadora sintetizou e integrou os insights contidos em todas as unidades de significado e as agrupou em temas ou categorias.

Os participantes foram selecionados de acordo com os seguintes critérios: adolescentes com IC agendados para retornar no período do segundo semestre de 2006 eprimeiro semestre de 2007, como rotina do acompanhamento interdisciplinar do Programa de Implante Coclear; com deficiência auditiva congênita; na faixa etária que caracteriza a adolescência, dos 12 aos 18 anos; e de ambos os sexos. Embora 8 adolescentes selecionados estivessem agendados, 3 adolescentes faltaram ao retorno e 1 não concordou em participar. Dessa maneira, os participantes foram 4 adolescentes usuários de IC, do sexo feminino, com deficiência auditiva congênita; 3 com etiologia de rubéola materna; e 1 idiopática; com idades no período da cirurgia que variaram de 3 anos e nove meses a 5 anos; com tempo de uso de IC entre 10 e 12 anos. Os dados de identificação das participantes foram levantados dos prontuários (Anexo).

Considerando-se que, no método fenomenológico, a coleta e análise dos dados ocorrem simultaneamente e que o critério de encerramento da coleta de dados é a repetição que expressa a essência do fenômeno (Boemer, 1994), neste estudo, a quarta entrevista foi suficiente para cumprir tal critério.

\section{Resultados e discussão}

O discurso manifesto na linguagem dos adolescentes com IC possibilitou perceber as convergências de suas falas e agrupá-las em unidades de significação dos conteúdos. Tal agrupamento, em categorias ou termos comuns, revelou a essência de suas experiências. Nessa perspectiva, as unidades de significado foram analisadas como segue:

\section{O contexto escolar:}

"Tô indo bem na escola, nunca bombei. Eu presto atenção na aula, se eu não entendi eu falo pra professora. [...] $\mathrm{Na}$ escola eu 
tenho dificuldade em algumas matérias. Por exemplo, Matemática, eu não tenho dificuldade, eu sou uma ótima aluna, só que Português tá complicado, as palavras são diferentes, tem palavras que são ambiguidade.” (1)

"Na escola tem o intérprete que dá o sinal, né? [...] eu ensino os meus amigos surdos, sabe, o sinal. Eu ajudo eles que não entendem. [...] Chama o professor, aí ele não entendeu, aí ele explica pra mim, aí, explico pra minhas amigas." (2)

"To estudando. [...] Eu gosto de estudar, mas é muita coisa, ensino médio é bem puxado. Eu tenho preguiça de estudar. [...] E o professor, depende da palavra, se fala rápido, aí a gente não entende. [...] Tô aprendendo outras matérias, é difícil, né?" (3)

"Eu tô no $1^{\circ}$ colegial. É meio puxado... É difícil, porque alguns professores falam rápido, muito rápido, e minha classe tem muito barulho, conversa. [...] Eu não consigo estudar sozinha. Eu pergunto pro professor, fala de novo, repetir. [...] Repete rápido de novo e não adianta. Aí você tem que ficar falando de novo, de novo. Aí não dá, né? [...] Eu estudo na apostila, mas tem que entender o que o professor explica, só que eu não entendo nada. A apostila é um pouco diferente, sabe? [...] Às vezes eu peço minha mãe. Mãe, tem que estudar. [...] A matéria é Química, minha mãe não sabe, não entende nada. Eu tenho uma irmã mais velha, ela tá fazendo cursinho, tá estudando pro vestibular, e ela me ajuda. [...] Fiz prova de todas as matérias, fui muito mal... notas baixíssimas. Aí eu conversei com os professores. 'Ah, eu não sabia, você é deficiente auditiva, tudo bem, eu posso ajudar você.' [...] Depois da prova, eu falei com os professores. [...] Meu coordenador, ele sabe que eu sou deficiente auditiva, porque meus pais foram conversar com ele. Aí ele: 'Eu não sabia, ah tudo bem, eu vou conversar com os professores pra pedir um trabalho, senão vai repetir o ano, e não pode'. [...] Eu achava que eles já sabiam que eu sou deficiente auditiva. [...] E agora eles vão ajudar, agora eles sabem." (4)

No discurso dessas adolescentes, as experiências do contexto escolar eram marcadas por dificuldades, especialmente em Língua Portuguesa, o que confirma o estudo de Gabriele \& Bevilacqua (2007). No entendimento da fala do professor - seja na discriminação das palavras, porque ele falava rápido, ou pela falta de vocabulário da pessoa com deficiência auditiva - a compreensão do todo e da disciplina, de modo geral, era prejudicada. As 
participantes 1 e 3 demonstraram conhecer suas habilidades e dificuldades, lidavam com naturalidade com a situação. No caso da participante 1, questionava o professor quando não entendia. Em relação à participante 2, a sua realidade escolar era diferente das demais participantes deste estudo: não era a única com deficiência auditiva na classe, e havia um intérprete, que traduzia a fala do professor em libras (língua brasileira de sinais). Assim, sentiase privilegiada em auxiliar os colegas com deficiência auditiva de sua sala, pois era a única que usava o IC e conseguia ouvir e falar. Fazia uso de libras para se comunicar com os colegas com deficiência auditiva e da linguagem oral para com os ouvintes, confirmando os estudos de D'Agosta et al. (1999) e Bosco et al. (1999), de que o IC auxilia no relacionamento com colegas, com professores e proporciona maior independência. Esse caso corrobora também os estudos que mostram que o IC tem contribuído para que os usuários possam frequentar salas de aula regulares e apresentar bom desempenho acadêmico e social (Nevins \& Chute, 1995; Francis et al., 1999).

No caso da participante 4, ficou claro o seu constrangimento em pedir várias vezes que o professor repetisse o que falou, e sentir que era em vão; também ficou patente a sua dificuldade em relação à língua falada e escrita, as dificuldades com o vocabulário, evidenciando-se que a interpretação e comunicação se tornavam difíceis para ela. Nesse caso, ela precisava de ajuda de um profissional que auxiliasse na interpretação da língua portuguesa, dificuldade comum para muitas pessoas com deficiência auditiva congênita. Segundo Yamada \& Bevilacqua (2005), embora o som obtido com o IC melhore a comunicação e a percepção sonora, é diferente do som que o ouvido humano naturalmente capta. Assim, a pessoa tem que lidar com esta e outras situações comuns no cotidiano da pessoa com deficiência auditiva, o que enseja pensar em alternativas para auxiliar no processo educacional.

O período da adolescência é marcado por uma turbulência em relação ao ser diferente: é a fase em que começa a acontecer uma conscientização maior sobre as implicações da deficiência auditiva (Balieiro \& Ficker, 2001).

Quando a participante 4 relatou que os professores não sabiam sobre sua deficiência auditiva e, após ter ido mal às provas, decidiu contar, revelou o quanto lhe era difícil falar e expor a deficiência auditiva. Para Romero (2003a), a vergonha é um dos sentimentos que emerge de imediato quando a pessoa é surpreendida num ato censurável. Ela se sente desfavorável, sente-se aquém de suas expectativas e das do grupo. Revela, também, a necessidade da ajuda dos familiares e professores no acompanhamento escolar. De acordo com Balieiro \& Ficker (2001), a maior parte das experiências do jovem acontece fora do ambiente familiar. Longe da família, enfrentam situações difíceis, nas quais 
é preciso conquistar amizades, suportar rejeição e perceber-se como alguém que tem um processo diferente dos demais. No ambiente de escola regular, o início da adolescência coincide com uma mudança na dinâmica de ensino, e a figura de um único professor é substituída por diferentes professores, um para cada disciplina, ocasião em que tudo parece ficar mais complexo.

\section{O contexto familiar:}

"A família tá ótima. A minha mãe é separada do meu pai, mas eles são amigos. Eu já sofri muito com isso, mas agora não. [...] O meu pai conversa com o namorado da minha mãe, e a minha mãe conversa com a namorada do meu pai." (1)

“... Minha mãe explicou pra mim que não precisa ter vergonha do implante. Por exemplo: quando você não conhece, a pessoa fala rápido, você não entende e pede pra falar mais devagar. [...] Por que eu uso o implante? Aí ela explicou tudo, e eu aprendi. [...] Eu não tenho mais vergonha. $\mathrm{O}$ aparelho é pra escutar." (2)

"Tá tudo bem, ótimo. Eu moro com a minha avó, em outra cidade. Eu morava em outra cidade. Mora minha vó, minha mãe e meu pai, só. Porque a outra casa, a gente tinha alugado, na época que eu morava em outro Estado, eu morei há quatro anos. Eu tenho muito parente, muita prima." (3)

"Eu sofri muito, porque meus pais são separados. Não gostei. Nós já sofremos muito. Foi difícil pra minha irmã, pra mim. Nossa família era unida e não deu certo, meus pais. Eu moro com a minha mãe, meu pai mora em outro apartamento. [...] Às vezes, eu não sabia o quê, minha mãe chorando, o que eu faço pra minha mãe. [...] Passou. [...] Minha família conversa comigo. Minha mãe me ajuda, ela me ensina falar, pra melhorar... A minha irmã mais velha está fazendo cursinho... e ela me ajuda com as matérias da escola." (4)

No contexto familiar, apareceu, no relato das adolescentes, a importância da comunicação e do relacionamento entre os membros da família, assim como o grau de satisfação com a dinâmica familiar atual. A questão da separação dos pais foi vivida com sofrimento pelas participantes 1 e 4 .

Para a participante 2, a relação mãe-filha era marcada pelo sentimento de compreensão diante das necessidades e questôes ligadas à deficiência auditiva e IC. Para Dias et al. (2000), a família é fundamental para o adolescente, por ser o primeiro e mais importante núcleo de influência socioafetiva; por excelência, 
é o lugar favorável ao seu desenvolvimento e formação, proporcionando-lhe o ambiente ideal para a socialização e a aprendizagem de valores, normas e comportamentos.

O contexto familiar, para a participante 4, significava um espaço de apoio nos momentos de dúvidas escolares e no desenvolvimento da fluência verbal. Lutermann (1987), audiologista que se envolveu no trabalho com famílias de deficientes auditivos, já afirmava que um dos principais valores de uma família é a comunicação clara e aberta, na qual os membros possam se compreender. Considerou uma família de sucesso aquela que percebe que sua ação pode fazer diferença e trazer conforto, ao compartilhar os sentimentos entre os seus membros.

\section{O namoro/ficar:}

"Agora ele tá ficando com a minha amiga, mas eu não tenho nada contra ela. [...] Mas tem um cara que tá a fim de mim. [...] Ele falou pro amigo dele que acha eu linda, que tava muito afim de mim, que queria ficar comigo. Falei pra ele que não dá certo, por causa do meu pai. Aí o que aconteceu, a gente ficou mais amigo, conversou muito, sabe. Aí passou tempo, a gente não se viu mais. [...] Ele falou pro amigo dele, outro amigo dele, que me achava muito linda, pra eu dar uma chance pra ele, aí ele conversou comigo, a gente acabou ficando. [...] Foi ótimo.” (1)

"Ele mentiu pra mim [ex-namorado], aí eu fiquei nervosa. O surdo é o pior comportamento. [...] Ele é nervoso, faz bagunça, fala palavrão, faz besteira. [...] Ele escreve no papel, sabe, aí eu não consigo, fica nervoso. Aí eu falei: chega, não quero mais. [...] Eu não quero namorar com você. Agora ele é meu amigo. [...] Ele tá com outra menina. [...] Agora estou namorando o R. [...] Nossa, todo mundo adora ele. [...] A conversa, o bate-papo, muito legal.” (2)

"Ele não quis ficar comigo... Ele não gosta de mim... Antes eu gostava muito, agora eu não gosto mais. $\mathrm{O}$ tempo esquece, não dá mole pra ele, né? Ele gosta de mim como amiga, toda semana converso com ele no MSN, mas eu não quero falar com ele, é muito chato, né? Ele não quis ficar comigo. [...] Não é fácil, primeiro estudar bastante, e namorando não estuda muito. Eu não tenho namorado..., e também eu quero estudar, né? Eu vou terminar de estudar, aí eu posso namorar. Eu acho que é melhor." (3)

"Nunca namorei. [...] Ele quis ficar comigo, só que depois não deu certo. Percebi que ele não era legal. Ele bebe muito. [...] Eu fui burra, cega. [...] Minha irmã ficou muito brava comigo, por causa de 
meninos. Falou que esse menino é só aproveitar comigo. A minha irmã queria alguém que me protege, pra cuidar, ficar junto e fazer feliz. Minha irmã tá namorando, sabe coisas, faz coisas certas. [...] Eu tô gostando de uma pessoa, e a pessoa não sabe que eu gosto dele. Eu tenho muita vergonha pra falar que eu uso implante coclear, tenho muita vergonha, não vou conseguir contar." (4)

O ficar é um relacionamento afetivo bastante popular entre os adolescentes e caracteriza-se por ser episódico, ocasional, passageiro, superficial, sem maiores consequências ou envolvimentos profundos (Justo, 2005; Mariano, 2001; Weingartner et al., 1995).

Como se pôde verificar pelas unidades de significado, as adolescentes com IC deste estudo experimentavam os fenômenos típicos da adolescência.

No caso da participante 4, observou-se a superproteção da irmã; a crença de que ela precisava de alguém que a protegesse e que cuidasse dela; e a interpretação de que "menino só quer aproveitar". Por outro lado, ela também demonstrou a crença de que a irmã é "quem sabe das coisas e faz coisas certas". Colocava-se na posição de quem "não sabe e não faz as coisas certas", ou seja, numa posição de inferioridade e incapacidade, confirmando o estigma da deficiência. Verbalizava sua vergonha em contar que usa o IC e sofria com isso. Conforme Romero (2003a), a vergonha indica que a pessoa se relaciona consigo mesma de modo desaprobatório e desvalorizante. Mostra que se sente inferior perante outra pessoa e sente-se incapaz e insegura diante da vontade de experimentar o que a vida oferece, especialmente no plano afetivo.

A participante 2 revelou não só uma dificuldade de comunicação com a pessoa surda como também o preconceito e estereótipo que legitimam a diferença e consequente exclusão daquele que tem limitações maiores de audição, fala e comunicação. Segundo a sua ótica, "o surdo tem seu comportamento pior, é nervoso, faz bagunça, fala palavrão e faz besteira...”

\section{A amizade:}

"Tenho bastante amigos. [...] Todo sábado e domingo, eu vou passear com meus amigos, eu saio, vou na boate também. [...] Eles gostam muito de mim, amigos verdadeiros mesmos. [...] Ligam pra ir me buscar, pra ir em churrasco na casa deles." (1)

"Eu gosto de conversar com meus amigos e passear com meus amigos. [...] Às vezes, com surdo, às vezes, com ouvinte; vamos passear, tudo junto, normal. [...] Eu converso com ouvinte e não faço sinal. [...] Os surdos convidam eu pra sair, os ouvintes saem comigo, aí eu saio, normal." (2) 
“... Eu gosto de internet, conversar, fazer novas amizades, conhecer pessoas, tem que aprender a falar. [...] Amigos é muito bom. Eles são muito legais comigo. Eles têm que saber sobre o implante, eu expliquei pra eles e entenderam. [...] Eu tenho uma prima, e ela tem bastante amigos, sabe, e elas são as minhas amigas. [...] Eu não gosto de ficar sozinha." (3)

“[...] Quando eu pego amizade, a pessoa não sabe que eu sou deficiente auditiva, depois descobriram. Só que as pessoas não fazem pergunta, como você ouve, como você tá escutando. Eles não fazem perguntas, e eu não falo nada. [...] Eu falo, fala de novo, repete que eu não entendo. [...] Eu acho que as pessoas não querem, a pessoa fala diferente como eu. [...] Teve um dia, as meninas, me excluíram, me deixaram sozinha. [...] Entrando na sala, ah, surda, tonta, que eu sou boba, enchem o saco. [...] Eu fico chateada, né? [...] Eu xingo, aí depois eu não ligo, não dá bola." (4)

A amizade com alguém, na concepção de Romero (2003b), revela que o outro é importante em alguma medida: não só atenua o sentimento de uma eventual solidão como permite a cada um perceber a sua importância social e como indivíduo.

De acordo com Guzman (2007), conforme crescem, os adolescentes são mais ativos em selecionar os ambientes que frequentam, nas decisões que tomam a respeito de seu comportamento e nos seus projetos de futuro. Uma maior autonomia permite ao adolescente selecionar suas companhias e amizades, frequentar ambientes sociais compatíveis com seus próprios interesses, assim como lhe permite ter influência nos ambientes de sua interação, seja seu grupo, escola ou família.

Em todos os relatos, ficou evidente a importância da amizade para as adolescentes. Conviver com amigos, sentirem-se aceitas e amadas por eles, conforme se percebe nas falas das participantes 1, 2 e 3, é fundamental na adolescência, período em que a opinião dos amigos ganha mais importância.

No que se refere à melhora na comunicação, no relacionamento interpessoal, na qualidade de vida e na autoconfiança, o IC teve uma contribuição significativa para essas adolescentes (Bosco et al., 1999; D'Agosta et al., 1999; Yamada, 2002; Huber, 2005).

De acordo com Guzman (2007), o bem-estar dos adolescentes não é resultado unicamente das fortalezas e vulnerabilidade de cada um, mas também das oportunidades e experiências de seus contextos vivenciais (família, escola, amizades), os quais oferecem recursos que contribuem para o seu desenvolvimento. 
Quando contou que foi excluída do grupo, ficou sozinha e sofreu xingamentos, a participante 4 minimizou a situação, dizendo que ficou chateada, que também xingou e que não dava bola. Nesse caso, evidenciouse como os rótulos negativos marcam, desqualificam e estigmatizam a pessoa com deficiência auditiva. A reação descrita demonstrou que a relação com o outro era permeada por sentimentos de inferioridade e de rejeição. É na comunicação que a diferença se faz presente: é o ter que pedir que o outro repita a fala, é o outro perceber que a fala é diferente. A aparência física da participante não indicava nada que mostrasse a sua deficiência: seus cabelos eram longos e soltos, não usava miniblusa, e a unidade externa do IC ficava em suas costas, por baixo da roupa.

Nesse sentido, confirma o que Murakami et al. (2001) e Yamada (2002) pontuaram sobre a estética do IC: é a dificuldade na comunicação que expõe e confirma a deficiência auditiva. A experiência de ser diferente pode ser extremamente difícil ao adolescente, especialmente porque é uma fase da vida em que se observa certa homogeneização entre os jovens, que se fazem parecidos por se sentirem parte de um grupo (Balieiro \& Ficker, 2001).

\section{A percepção do implante coclear:}

"Eu não tenho vergonha de usar o aparelho. [...] Eu acho que esse implante é muito bom, pra querer escutar, pra falar com meu pai no telefone direitinho. Ele ajuda a ouvir o professor que tá falando a matéria nova, essas coisas. [...] Eu falo superbem. [...] Eu entendo tudo. [...] Eu carrego quatro pilhas. [...] Eu falo que eu tenho problema de audição, que antes eu não escutava nada, que minha mãe sofreu uma doença, rubéola, explico tudo o que aconteceu, que eu vim pra Bauru, fiz o implante pra mim ouvir, pra entender." (1)

"Eu gosto de usar o aparelho, o implante, eu adoro! Eu sempre uso. As amigas chamam e eu escuto. [...] Ele [professor] nunca viu, aí eu mostrei e ele falou: você escuta bem! [...] Eu mostro pra eles [amigos], explico. [...] Antes eu tinha vergonha, agora não tenho. [...] Minha mãe explicou que não precisa ter vergonha. Por exemplo, quando você não conhece, a pessoa fala rápido, você não entende, pede pra falar devagar, aí eu perdi a vergonha. [...] Vergonha é ficar sem escutar os amigos." (2)

"O implante tá tudo ótimo, pra ouvir, pra entender. [...] Às vezes tá muito barulho e eu não gosto, aí não ouve. [...] Não gosto de muito barulho porque o professor chama e não ouve, se tiver 
muita bagunça. [...] O guri que não conhece o implante acha que é uma pessoa que tem problema, não é isso. É o mesmo dos óculos, que não enxerga, o óculos ajuda. Eu falo o que é aparelho, que eu escuto bem." (3)

"Eu acho importante pra pessoa usar o implante coclear, ouvir, falar, fazer mais amizades. Faz 12 anos que eu uso o implante. [...] Conversar com pessoas, ouvir barulho. É essencial pra pessoa usar o implante coclear. [...] Pra fazer mais amizades. [...] Eu acho ruim ficar sem ouvir nada, é difícil pra pessoa falar sinais. [...]. Quando perguntam, tem que contar. [...] Eu gosto do implante. É bom pra mim.” (4)

As adolescentes deste estudo percebiam o benefício do IC e revelaram satisfação em poder ouvir. A possibilidade de falar ao telefone, de ouvir a voz de uma amiga, poder ouvir o professor e acompanhar as matérias da escola, escutar e compreender, situações comuns para o ouvinte, têm um significado especial para essas adolescentes. O IC para elas significava a possibilidade de participar do mundo sonoro, ampliar sua comunicação com o outro, melhorar sua qualidade de vida e bem-estar, enfim, um considerável progresso na autoconfiança (Yamada, 2002; Huber, 2005; Sant’Anna, 2008).

A percepção dos benefícios proporcionados corroboram os estudos realizados por Nasralla et al. (2008) com adolescentes candidatos ao IC, que encontrou resultados semelhantes: a aceitação da surdez, o desejo de ser implantado acompanhado da consciência e da capacidade de enfrentar angústias e desafios, e de assumir a própria individualidade.

Os resultados também confirmaram os estudos de Murakami et al. (2001) sobre expectativas prévias de adolescentes candidatos a IC e suas avaliações posteriores quanto a ganhos obtidos com o implante: todos afirmaram satisfação com o IC, pela ajuda na audição; relataram que suas vidas se transformaram para melhor e que estavam muito felizes.

No relato da participante 2 ficou claro que experimentava o sentimento de vergonha como usuária do IC e como buscava atenuar isso quando dizia que "vergonha é ficar sem escutar os amigos".

Observou-se que, no relato da participante 4, embora revelasse que "é ruim ficar sem ouvir nada", em alguns momentos usava a terceira pessoa: "é essencial pra pessoa usar o IC... pra fazer mais amizades... tem que contar..." Isso pode significar o desejo do outro, a "voz" do outro - que pode indicar a "voz" da mãe, da sociedade ou a sua própria voz interna - revelando dificuldade de aceitação da deficiência auditiva, como mostrado nos relatos anteriores. Tais 
sentimentos corroboram os resultados encontrados por Yamada (2002), que verificou que a pessoa com surdez pode se sentir inferior perante o ouvinte, experiência derivada da percepção de uma deficiência, do juízo negativo dos outros e de algum fracasso.

\section{Conclusão}

Analisando os relatos das experiências mais significativas das adolescentes com IC, este estudo concluiu que o contexto escolar era marcado por dificuldades, especialmente no entendimento da língua portuguesa; pelo constrangimento em pedir ao professor que repetisse a sua fala e expor a deficiência auditiva; pelos benefícios do intérprete em libras, em alguns casos; e pela necessidade de ajuda para acompanhamento escolar. Pedir ao professor que repetisse foi apontado como uma solução natural para algumas e constrangedora para outras. Buscar ajuda na família foi outro aspecto apontado pelas participantes.

O contexto familiar era vivido por elas como um espaço de apoio, em que podiam discutir as suas necessidades e serem auxiliadas, especialmente nas questôes relacionadas à deficiência auditiva.

No relacionamento afetivo (namoro/ficar), todas haviam experimentado esse fenômeno típico da adolescência, e as questôes da deficiência auditiva foram marcadas pelos sentimentos de vergonha, inferioridade e pelo preconceito e estereótipo.

A importância da amizade era evidente para todas as adolescentes deste estudo, concluindo-se que o IC favoreceu a comunicação e o relacionamento interpessoal. No entanto, a experiência da exclusão e rejeição também fazia parte da realidade vivida por elas, assim como o estigma da deficiência.

O IC para as participantes significava satisfação - referiram-se à importância de ouvir a voz das pessoas, de falar ao telefone, de acompanhar melhor os estudos - e, por outro lado, significava a constatação da deficiência auditiva e da dificuldade de aceitação.

Em suma, o estudo revelou como essas adolescentes com deficiência auditiva e usuárias de IC estavam vivendo as questôes que permeavam o fenômeno adolescer, embora, em sua individualidade, cada uma em particular o experimentou de forma singular e mostrou como os aspectos emocionais interferiam em todos os contextos que são significativos nessa etapa da vida: escola, família, namoro, "ficar", amizade e implante coclear.

Ainda que o estudo confirme os benefícios do IC, observa-se a importância 
de olhar o paciente em sua integridade de ser humano constituído de sentimentos, emoções e subjetividade.

Como conclusão, destaca-se a importância da continuidade do grupo de adolescentes com IC nos seus retornos anuais no CPA-HRAC-USP, sugere-se um trabalho de conscientização que vise à intervenção psicológica na cidade de origem e o desenvolvimento de outras pesquisas que tenham por objetivo aprofundar as investigaçóes nos contextos que emergiram deste trabalho. Certamente este estudo pode contribuir com os familiares e profissionais envolvidos, dando a conhecer um pouco da experiência desses adolescentes e propiciando uma compreensão mais ampla do que é ser adolescente com IC.

\section{Referências}

Balieiro, C. R. \& Ficker, L. B. (2001). O adolescente deficiente auditivo: algumas reflexões da clínica fonoaudiológica. In: V. R. J. R. M. Fonseca. Surdez e deficiência auditiva: a trajetória da infância à idade adulta. (pp. 159183). São Paulo: Casa do Psicólogo.

Bevilacqua, M. C., Costa Filho, O. A. \& Martinho, A. C. F. (2004). Implante coclear. In: L. P. Ferreira. Tratado de fonoaudiologia. (pp. 751-761). São Paulo: Roca.

Costa Filho, O. A \& Bevilacqua, M. C. (2006). Otorrinolaringologia: princípios e prática. (pp. 447-453). Porto Alegre: Artmed.

Bicudo, M. A. V. (2000). Fenomenologia: confrontos e avanços. São Paulo: Cortez.

Boemer, M. R. (1994). A condução de estudos segundo a metodologia fenomenológica. Revista Latino-Americana de Enfermagem, 2 (1), 83-94.

Bosco, E., D’Agosta, L. \& Ballantyne, D. (1999). “Small group” rehabilitation in adolescent cochlear implant users: learning experiences. International Journal of Pediatric Otorhinolaryngology, 47 (2), 187-190.

D’Agosta, L., Bosco, E. \& Cordier, A. (1999). "Small group" rehabilitation in adolescent cochlear implant users: aims, method and results. International Journal of Pediatric Otorhinolaryngol, 47, 191-194.

Dias, M. D. F., Robles, R. A. M. \& Ferreira, T. H. S. (2000). Adolescência e 
família. Pediatria Moderna, 36 (11), 721-722.

Francis H. W., Kock M., Wyatt R. \& Niparko J. (1999). Trends in educational placement and cost-benefit considerations in children with cochlear implants. Archives of Otolaryngology: Head and Neck Surgery, 125, 499-505.

Gabriele, D. P. F. \& Bevilacqua, M. C. (2007). Crianças deficientes auditivas usuárias de implante coclear multicanal e o contexto escolar. Temas sobre desenvolvimento, 15 (89/90), 85-91.

Guzman, M. L. M. (2007). Mirando al Futuro: desafíos y oportunidades para el desarrollo de los adolescentes en Chile. Psykhe, 2007, 16(1), 3-14. Recuperado em 13 de julho, 2008, de http://www.scielo.br//scielo.php?script=sci_ arttext\&pid=S0718222820070001 00001\&lng=pt\&nrm=iso.

Huber, M. (2005). Health-related quality of life of Austrian children and adolescents with cochlear implants. International Journal of Pediatric Otorhinolaryngol, 69 (8), 1089-1101.

Justo, J. S. (2005). O "ficar" na adolescência e paradigmas de relacionamento amoroso da contemporaneidade. Revista do Departamento de Psicologia da UFF, 17 (1), 61-77.

Lutermann, D. (1987). Deafness in the family. Boston: College-Hill.

Mariano, C. L. S. (2001). Um estudo sobre os relacionamentos amorosos na adolescência. Dissertação de mestrado, Programa de Pós-graduação em Psicologia, Universidade Estadual Paulista "Júlio de Mesquita Filho", Assis.

Martins, J. \& Bicudo, M. A. V. (1989). A modalidade fenomenológica de conduzir pesquisa em psicologia. In: J. Martins \& M. A. V. Bicudo. A pesquisa qualitativa em Psicologia: fundamentos e recursos básicos. (pp. 93-95). São Paulo: Moraes.

Murakami, G. A. O., Neme, C. M. B., Yamada, M. O. \& Bevilacqua, M. C. (2001). Expectativas prévias ao implante coclear e avaliação pós-implante em adolescentes. Estudos de Psicologia, 18 (2), 5-16.

Nasralla, H. R, Goffi, V., Guedes, M. C. \& Peralta, C. G. O. (2008). Implante Coclear na adolescência: quatro candidatos, quatro percursos ao Implante Coclear. Arquivos Internacionais de Otorrinolaringologia, 12 (1), 126-132.

Nevins, M. E. \& Chute, P. M. (1995). Success of children with cochlear implants 
in mainstream educational settings. The Annals of otology, rhinology, and laryngology. 166, 100-102.

Romero, E. (2003a). As formas da sensibilidade: emoções e sentimentos na vida humana. São José dos Campos: Della Bídia.

Romero, E. (2003b). Neogênese: o desenvolvimento pessoal mediante a psicoterapia. São José dos Campos: Della Bídia.

Romero, E. (2005). Estações no caminho da vida: o desenvolvimento dos afetos nas diversas etapas da vida. São José dos Campos: Della Bídia.

Sant'Anna, S. B. G., Eichner, A. C. O. \& Guedes, M. C. (2008). Benefício do implante coclear em indivíduos adultos com surdez pré-lingual. O Mundo da Saúde, 32 (2), 238-242.

Seifert, E., Kollbrunner, J., Mantokoudis, G., Vischer, M. \& Kompis, M. (2008). The tolerante of ambiguity in late cochlear-implanted pre-lingually deaf juveniles. Departament of Otorhinolaryngology, head and neck Surgery, Inselspital. University of Berne, Berne, Switzerland. Clinical Otolaryngology, 33, 239-244.

Tirado Gutiérrez, C. \& Soda Merhy, A. (2001). Expectativas del implante coclear. Revista del Instituto Nacional de Enfermedades Respiratórias, 14 (3), 160-163.

Weingartner, C. L., John, D., Bonamigo, L. R. \& Goidanich, M. (1995). O ficar e o namorar vistos pelos adolescentes. In: J. S. Justo (2005). O "ficar" na adolescência e paradigmas de relacionamento amoroso da contemporaneidade. Revista do Departamento de Psicologia - UFF, 17 (1), 61-77.

Yamada, M. O. (2002). Dimensão afetiva, segundo a concepção de Emílio Romero, da pessoa com surdez adquirida antes e após o uso do implante coclear. Dissertação de mestrado, Hospital de Reabilitação de Anomalias Craniofaciais, Universidade de São Paulo, Bauru.

Yamada, M. O. \& Bevilacqua, M. C. (2005). O papel do psicólogo no programa de implante coclear do Hospital de Reabilitação de Anomalias Craniofaciais. Estudos de Psicologia, 22 (3), 255-262.

\section{Anexo:}

\section{Identificação dos participantes.}




\begin{tabular}{|c|c|c|c|c|c|}
\hline Sujeito & $\begin{array}{l}\text { Idade } \\
\text { (anos) }\end{array}$ & Escolaridade & Etiologia & $\begin{array}{l}\text { Idade na } \\
\text { cirurgia }\end{array}$ & $\begin{array}{c}\text { Tempo de uso } \\
\text { do IC }\end{array}$ \\
\hline 1 & 15 & $\begin{array}{c}1^{\circ} \text { ano do ensino } \\
\text { médio }\end{array}$ & Rubéola mater & $\begin{array}{c}4 \text { anos e } 9 \\
\text { meses }\end{array}$ & $\begin{array}{c}10 \text { anos e } 6 \\
\text { meses }\end{array}$ \\
\hline 2 & 13 & $\begin{array}{l}7^{\mathrm{a}} \text { ano ens. } \\
\text { fundamental }\end{array}$ & Idiopática & $\begin{array}{c}3 \text { anos e } 9 \\
\text { meses }\end{array}$ & 10 anos \\
\hline 3 & 15 & $\begin{array}{c}1^{\circ} \text { ano do ensino } \\
\text { médio }\end{array}$ & Idiopática & 5 anos & 11 anos \\
\hline 4 & 16 & $\begin{array}{c}2^{\circ} \text { ano do ensino } \\
\text { médio }\end{array}$ & Idiopática & $\begin{array}{c}4 \text { anos e } 2 \\
\text { meses }\end{array}$ & 12 anos \\
\hline
\end{tabular}

